\title{
Genetic evidence for different scales of connectivity in a marine mollusc
}

\author{
Maxine P. Piggott*, Sam C. Banks, Peter Tung, Luciano B. Beheregaray \\ Molecular Ecology Group for Marine Research, Department of Biological Sciences, Macquarie University, Sydney, \\ New South Wales 2109, Australia
}

\begin{abstract}
Recent studies of connectivity in marine populations have suggested that larval retention and local recruitment are more common than previously considered. Here we used genetic data to investigate the scale of connectivity and patterns of recruitment in the abalone Haliotis Coccoradiata, a broadcast spawner with a short larval stage. Although we detected weak but significant genetic differentiation $\left(F_{\mathrm{ST}}\right)$ between populations over a scale of approximately $1000 \mathrm{~km}$, the pattern did not fit an isolation-by-distance (IBD) model, suggesting relatively long dispersal distances. However, individual-based multilocus spatial autocorrelation identified fine-scale genetic structure within a range of $20 \mathrm{~km}$, suggesting short distance dispersal and local recruitment. Simple computer simulations in which all dispersal was restricted to within this scale (mean $10 \mathrm{~km}$ ) suggested that a significant IBD result would most likely be generated under such a dispersal scenario. The lack of a significant IBD suggests infrequent long-distance dispersal is also likely and this is further supported by oceanographic particle dispersal modelling, which shows that larvae could be transported over large distances by ocean currents. Our results suggest that recruitment occurs primarily over a small spatial scale in a species that also has the ability to disperse over considerably greater distances.
\end{abstract}

KEY WORDS: Abalone · Dispersal · Genetic structure $\cdot$ Recruitment $\cdot$ Microsatellite DNA

\section{INTRODUCTION}

Accurately assessing dispersal in the marine environment is essential for understanding local population dynamics and the spatial scale of genetic population structure. Gene flow and population structure in sedentary or sessile marine species are largely dependent on the dispersal ability of larvae (Palumbi 2003, Banks et al. 2007). Dispersal capability is influenced by larval life history (Bell \& Okamura 2005) and behaviour (e.g. larval swimming) (Palumbi 2003), ocean currents (Palumbi 1994) and the ecological requirements of a species (e.g. food availability) (Shepherd \& Laws 1974). For species with long-lived pelagic larvae, it might be expected that the oceanic environment will encourage long-distance dispersal and low genetic structure (Palumbi 2003). However, mounting evidence suggests that long-distance dispersal may be rarer than expected (Palumbi 2003). Recent studies have shown that local recruitment or larval retention is quite common, even for species with long-lived larvae (Hellberg et al. 2002). Therefore, relying on larval life histories to predict dispersal may not provide an accurate interpretation of larval dispersal distances (Bell \& Okamura 2005). In this regard, classifying species as being long- or short-distance dispersers or as having closed or open populations may in reality be simplifying a more complex underlying population structure (Kinlan et al. 2005).

Assessing dispersal in the marine environment is important for sustainable management of marine resources and design of marine reserves (Palumbi 2003). The observation that larval retention and local recruitment is more common than previously expected has consequences for fisheries management and reserve design. Although larval retention reduces the dependence on immigration from other populations for recruitment, it may also reduce the potential for 
recolonisation of areas subjected to overfishing (Prince et al. 1987). Evidence for local recruitment in the marine environment has come from a variety of sources, including ecological studies (Swearer et al. 1999, Sponaugle et al. 2005), genetic differentiation among local populations (Jones et al. 2005, Chambers et al. 2006), spatial autocorrelation showing spatial clustering of genotypically similar individuals (Underwood et al. 2007) and particle dispersal simulation studies (Stephens et al. 2006).

In this study we measure genetic structure at a range of scales to infer the degree of connectivity among populations of the abalone Haliotis coccoradiata along the New South Wales coast of Australia. Abalones are dioecious broadcast spawners with pelagic non-feeding larvae (McShane 1992). The short larval period (3 to 15 d), short reproductive window and limited adult movement reported for Haliotis spp. suggest limited dispersal capability (McShane 1992, Chambers et al. 2006). In addition, abalone are reported to settle exclusively on coralline algae (Shepherd \& Turner 1985), as chemicals available only on the surfaces of coralline algae have induced settlement and metamorphosis of abalone in the laboratory (Morse \& Morse1984).

Ecological and hydronamic studies of a closely related species, Haliotis rubra, have shown low dispersal of the planktonic larvae and recruitment on a local scale (Prince et al. 1987, McShane et al. 1988). A recent genetic study by Temby et al. (2007) also found that dispersal of $H$. rubra larvae is highly localized. This appears to contradict laboratory trials with $H$. rubra and larval biology studies of other haliotid species that suggest longer dispersal capabilities (McShane 1992, Roberts \& Lapworth 2001). Connectivity among populations is also likely to be influenced by other factors, such as local ocean current patterns. We sampled throughout the species' distribution $(\sim 1000 \mathrm{~km})$ and assessed genetic structure using methods based on allele frequency differentiation $\left(F_{\mathrm{ST}}\right)$ and multilocus genotypic arrays (spatial autocorrelation). The latter may be more sensitive to contemporary patterns of local scale dispersal, while $F_{\mathrm{ST}}$-based analyses may better estimate longer-term patterns over large scales.

\section{MATERIALS AND METHODS}

Sampling. A total of 226 Haliotis coccoradiata were collected from under boulders on sub-tidal rocky reefs from 11 locations extending from northern to southern New South Wales, Australia (Fig. 1, Table 1). At each site, abalone were sampled by divers on SCUBA or snorkel within a $\sim 50$ to $100 \mathrm{~m}$ radius. The most southerly and northerly sampling localities are approximately $1000 \mathrm{~km}$ apart, a sampling regime that effectively covers the distribution of the species (Edgar 2000). This species was scarcer in the northern part of its range due to less suitable rocky reef habitat. We attempted to sample at 3 locations north of the South West Rocks sites (towards Byron Bay, $28.61^{\circ} \mathrm{S}, 153.63^{\circ} \mathrm{E}$ ), but were only able to collect 2 individuals, which were not included in the analysis. Distances between sampling sites ranged from 8 to $1000 \mathrm{~km}$. A small tissue sample was taken from the foot of each individual and the animals were returned to the reef habitat whenever possible. Samples were stored in $100 \%$ ethanol.

DNA extraction and microsatellite genotyping. DNA extraction of Haliotis coccoradiata tissue was carried out using a modified 'salting out' method (Sunnucks \& Hales 1996). We screened 24 microsatellite loci previously developed for $H$. rubra (Evans et al. 2000, Baranski et al. 2006) using polymerase chain reactions (PCRs). PCRs contained $1 \mu \mathrm{l}$ of DNA, $200 \mu \mathrm{M}$ of dGTP, dTTP and dCTP and $20 \mu \mathrm{M}$ of dATP, $2.5 \mathrm{mM}$ $\mathrm{MgCl}_{2}, 10 \mathrm{mM}$ Tris- $\mathrm{HCl}(\mathrm{pH}$ 8.3), $50 \mathrm{mM} \mathrm{KCl}, 5 \mathrm{pmol}$ of each primer, $0.1 \%$ Triton X-100, $0.05 \mu l\left[{ }^{33} \mathrm{P}\right]$-dATP at $1000 \mathrm{Ci} \mathrm{mmol}^{-1}$ and 0.5 units of Taq DNA polymerase, in a total volume of $10 \mu$. Reaction conditions included initial denaturation at $95^{\circ} \mathrm{C}$ for $5 \mathrm{~min}$, denaturation at $95^{\circ} \mathrm{C}$ for $30 \mathrm{~s}$, annealing for $30 \mathrm{~s}$, extension at $72^{\circ} \mathrm{C}$ for $45 \mathrm{~s}$ for 30 cycles and a final extension step at $72^{\circ} \mathrm{C}$ for

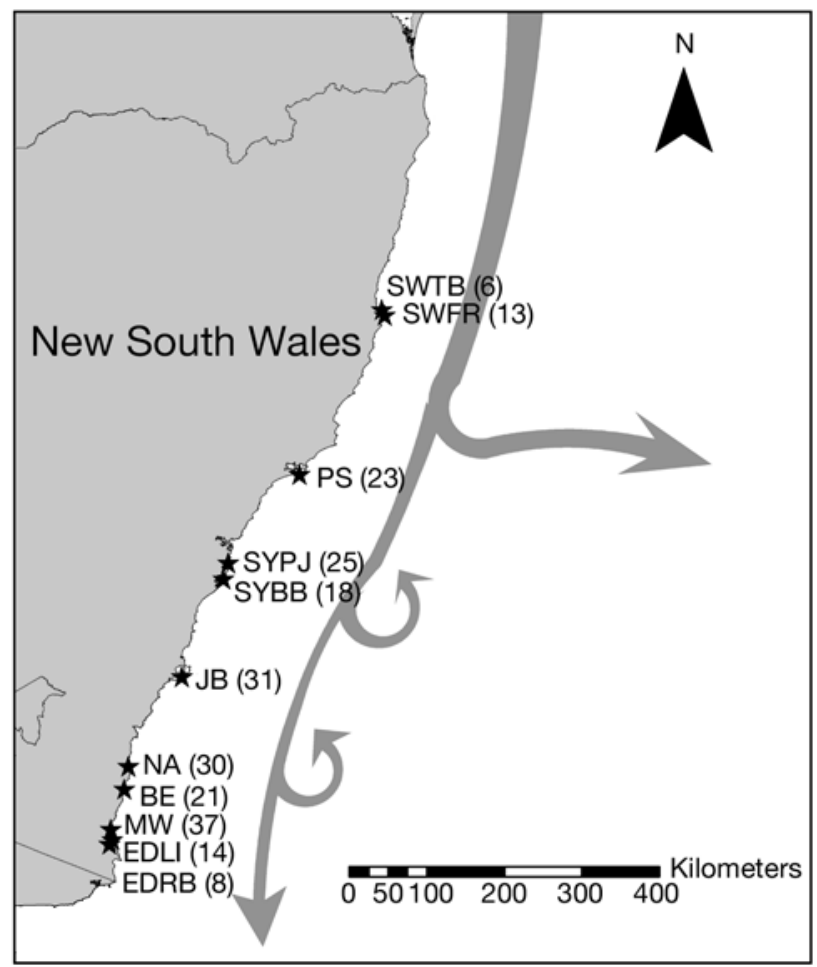

Fig. 1. Haliotis coccoradiata. Sampling sites and sample sizes along the east coast of New South Wales (see Table 1 for the full names and coordinates of sites). Grey arrow: East Australian Current 
Table 1. Haliotis coccoradiata. Sampling sites and coordinates for individuals collected along the east coast of New South Wales

\begin{tabular}{|lcc|}
\hline Site & Abbreviation & Location \\
\hline South West Rocks Trial Bay & SWTB & $30.94^{\circ} \mathrm{S}, 153.10^{\circ} \mathrm{E}$ \\
South West Rocks Fish Rock & SWFR & $30.94^{\circ} \mathrm{S}, 153.10^{\circ} \mathrm{E}$ \\
Port Stephens & PS & $32.72^{\circ} \mathrm{S}, 152.14^{\circ} \mathrm{E}$ \\
Sydney Port Jackson & SYPJ & $33.81^{\circ} \mathrm{S}, 151.29^{\circ} \mathrm{E}$ \\
Sydney Botany Bay & SYBB & $33.99^{\circ} \mathrm{S}, 151.23^{\circ} \mathrm{E}$ \\
Jervis Bay & JB & $35.13^{\circ} \mathrm{S}, 150.75^{\circ} \mathrm{E}$ \\
Narooma & NA & $36.17^{\circ} \mathrm{S}, 150.13^{\circ} \mathrm{E}$ \\
Bermugui & BE & $36.43^{\circ} \mathrm{S}, 150.08^{\circ} \mathrm{E}$ \\
Merimbula & MW & $36.90^{\circ} \mathrm{S}, 149.93^{\circ} \mathrm{E}$ \\
Eden Leonard Island & EDLI & $37.02^{\circ} \mathrm{S}, 149.94^{\circ} \mathrm{E}$ \\
Eden Ross Bay & EDRB & $37.07^{\circ} \mathrm{S}, 149.91^{\circ} \mathrm{E}$ \\
\hline
\end{tabular}

tions was calculated based on the estimator $\theta$ (Weir \& Cockerham 1984) and significance was determined with 10000 permutations.

An isolation-by-distance (IBD) model has been suggested as appropriate for investigating marine dispersal (Palumbi 2003). To assess whether there is a statistically significant association between genetic differentiation and geographic distance of the 11 populations we used the IBD option in GENEPOP 3.4 (Raymond \& Rousset 2003) to test the significance of the relationship between $F_{\mathrm{ST}}$ and geographic distance among populations. For geographical distances, we calculated the shortest distance in the marine environment without

5 min for all PCRs. Annealing temperatures are given in Table 2. PCR products were electrophoresed through a $6 \%$ polyacrylamide sequencing gel and visualized by autoradiography. Allele sizes were scored against an A- or T-terminating M13 control sequencing reaction size marker. As homozygote excesses and null alleles are common in marine invertebrate studies, in particular for Haliotis abalones (Chambers et al. 2006), we used MICRO-CHECKER 2.2.3 software (Shipley 2003) to check for evidence of null alleles in our microsatellite data following the approach of Brookfield (1996).

Genetic variation. Allele frequencies, the number of alleles per locus $(\mathrm{Na})$, expected $\left(H_{\mathrm{E}}\right)$ and observed heterozygosity $\left(H_{\mathrm{O}}\right)$ were calculated for each population using the program GENEPOP 3.4 (Raymond \& Rousset 2003). Multilocus $F_{\text {IS }}$ was also calculated for each population using GENEPOP 3.4, then tested by permutation using Weir \& Cockerham (1984) estimator. To test for conformance to Hardy-Weinberg expectations (HWE) we used GENEPOP 3.4, employing the Markov chain method of Guo \& Thompson (1992) at each combination of locus and population. Multilocus genotypes were tested for linkage disequilibrium (option 2), using GENEPOP 3.4 (Raymond \& Rousset 2003). Genotypes for each pair of loci were tested for independence in each population using a contingency test and significance values were calculated using Fisher's exact test.

Analyses of population genetic differentiation. An analysis of molecular variance (AMOVA) was carried out using ARLEQUIN 2.0 (Schneider et al. 2000) to determine the proportion of genetic differentiation distributed among the 11 populations. We jackknifed over loci by removing 1 locus at a time to determine if significance patterns were driven by outlier loci. Genetic differentiation $\left(F_{\mathrm{ST}}\right)$ between each pair of popula- crossing land between all pairs of sampling sites. Significance of the IBD pattern was tested on 10000 permutations of the data.

Multilocus spatial autocorrelation analysis. We conducted multilocus spatial autocorrelation analysis using GenAlEx version 6 (Peakall \& Smouse 2006). An autocorrelation coefficient $(r)$ was calculated for separate distance classes based on pairwise geographic and genetic distance matrices to provide a measure of spatial clustering of genotypically similar individuals (Smouse \& Peakall 1999). We conducted a single spatial autocorrelation analysis over all sites and samples, calculating $r$ among individuals sampled at the same locality $(0 \mathrm{~km})$ and separated by distances binned between the following intervals: 20, 40, 80, 100, 200, 400, 600, 800 and $1000 \mathrm{~km}$. This analysis was jackknifed over loci to determine whether the overall pattern of spatial autocorrelation was driven by specific outlier loci.

Computer simulations. We used computer simulations to assist with our interpretation of the biological processes that generate the detected patterns of genetic structure. As shown in our results, genotypic spatial autocorrelation analyses identified short scale genetic structure suggestive of local recruitment. However, large-scale genetic differentiation was weak

Table 2. Annealing temperatures and size range of alleles for 5 microsatellite loci designed for Haliotis rubra (Baranski et al. 2006) and used in this study for H. coccoradiata

\begin{tabular}{|lcccc|}
\hline \multirow{2}{*}{ Locus } & \multicolumn{2}{c|}{ Annealing temp. $\left({ }^{\circ} \mathrm{C}\right)$} & \multicolumn{2}{c|}{ H. coccoradiata alleles } \\
& Baranski et al. (2006) & This study & Size range (bp) & No. \\
\hline Hr12B10 & 55 & 55 & $192-243$ & 28 \\
Hr9B05 & 55 & 60 & $170-268$ & 14 \\
Hr10G10 & 55 & $55 \rightarrow 47^{\mathrm{a}}$ & $154-213$ & 27 \\
Hr13F06 & 55 & $55 \rightarrow 50^{\mathrm{b}}$ & $196-232$ & 19 \\
Hr11A10 & 55 & $55 \rightarrow 50^{\mathrm{b}}$ & $185-201$ & 11 \\
a Touchdown amplification, decrease by $2^{\circ} \mathrm{C}$ & & \\
bouchdown amplification, decrease by $1^{\circ} \mathrm{C}$ & & \\
\hline
\end{tabular}


and did not follow an IBD pattern suggestive of longdistance dispersal. We used simple computer simulations to estimate whether the large-scale pattern of no IBD could persist if dispersal were restricted to the scale over which we identified positive genotypic spatial autocorrelation.

We used EASYPOP (Balloux 2001) to generate the synthetic data sets with 5 different migration rates. A spatial model with 56 subpopulations in a linear arrangement was simulated. The populations consisted of 100 individuals (50 males and 50 females) and were spread at equal intervals over a $1000 \mathrm{~km}$ range. Random mating was simulated for each generation to produce a diploid genotype for each individual. For each parameter set, we simulated 5 loci with the same mutation dynamics: a mixed model of single step mutations with $0.5 \%$ of mutation events following an infinite allele model (Di Rienzo et al. 1994). The mutation rate was set at 0.005 (Jarne \& Lagoda 1996) and the maximum number of alleles was set at 15, similar to the genetic diversity in our data set. The genetic variability of the initial population was set at maximal, where genotypes are randomly assigned from all possible allelic states. The mean dispersal distance was the same for males and females $(10 \mathrm{~km})$. Five different migration rates (i.e. the proportion of migrants, 0.01 , $0.05,0.1,0.25$ and 0.5$)$ were tested. We ran each replicate for 1000 generations and then collected the genetic data for 30 individuals $(15$ males and 15 females) from the populations that corresponded to our 11 'real' sampling sites. Equal sex ratios and random mating may be unrealistic assumptions, but simulated sub-populations of only 100 individuals may represent much larger populations with small effective-to-actual population-size ratios. This is consistent with evidence of a low ratio of effective-to-actual population size in high-fecundity broadcast-spawning taxa as a result of high reproductive variance (Flowers et al. 2002). We analysed 50 replicates for each parameter set, using the IBD option in GENEPOP 3.4 (Raymond \& Rousset 2003) to assess whether there is a statistically significant association between genetic similarity and geographic distance, and calculated the percentage of replicates that gave a significant IBD p-value.

Particle dispersal modelling. We used the Australian Connectivity Interface (Aus-ConnIe) (Condie et al. 2005) (available from www.per.marine.csiro.au/ aus-connie) to estimate the dispersal distances possible for particles with a planktonic duration similar to Haliotis coccoradiata larvae. Aus-Connle provides an estimate of the probability that any 2 regions of the upper water column are connected over a specified dispersion period based on estimated ocean currents along the east coast of Australia, excluding local influences such as tides (Condie et al. 2005). Therefore this estimate represents the maximum dispersal distance that is likely to be achieved by this species. The AusConnIe database does not incorporate near-shore current processes, such as local eddies, or larval behaviour, such as vertical swimming. Therefore the predictions were simply used to provide an estimated upper limit for the potential dispersal scale of the species. We used an estimated dispersion period of $10 \mathrm{~d}$, as laboratory trials of settlement competency for $H$. rubra have inferred a dispersal phase of 3 to $15 \mathrm{~d}$ (McShane 1992), and determined the maximum dispersal likelihood along the New South Wales coast for 3 different locations from the north to the south (South West Rocks, Sydney Port Jackson and Jervis Bay). Dispersal probabilities were calculated for the months of November, January and March for the 3 populations - assuming peak reproductive behaviour at the beginning and end of summer (Ault 1985, McShane 1992) — and this was carried out over the 5 yr period on the interface (1995 to 1999).

\section{RESULTS}

\section{Number of DNA markers}

From the panel of 24 microsatellite loci originally developed for Haliotis rubra (Evans et al. 2000, Baranski et al. 2006), we found 5 markers to be polymorphic and easily scoreable: Hr12B10, Hr9B05, Hr10G10, Hr13F06, and Hr11A10 (Baranski et al. 2006). Of the remaining loci, 6 were polymorphic but difficult to score: Hr7G05, Hr10E02, Hr1D03 (Baranski et al. 2006), Hr2.14, Hr2.36, and Hr2.9 (Evans et al. 2000); 3 were monomorphic: Hr16G08, Hr4H11, and Hr1.11 (Baranski et al. 2006); and 10 failed to amplify or produce scoreable bands: Hr9E04, Hr2G01, Hr16G01, Hr2B01, Hr9G01 (Baranski et al. 2006), Hr1.25, Hr2.30, Hr1.24, Hr2.26, and Hr1.14 (Evans et al. 2000). The relatively extensive effort in marker screening conducted in our study exemplifies the difficulties in obtaining a large set of usable microsatellite DNA markers for some marine invertebrates and in particular for Haliotis abalones. This is corroborated by a recent genetic study of $H$. rubra in which only 3 species-specific microsatellite loci that were unlikely to have null alleles were considered appropriate for use (Temby et al. 2007).

\section{Genetic variation}

Fifteen out of 55 population-locus combinations deviated from HWE, and all 11 populations deviated from HWE and showed significant homozygote ex- 
Table 3. Haliotis coccoradiata. Analysis of molecular variance (AMOVA) for 11 populations for 5 microsatellite loci. Fixation indices: $F_{\mathrm{IS}}: 0.092 ; F_{\mathrm{ST}}: 0.009$; $F_{\text {IT }}: 0.101$

\begin{tabular}{|lrrcc|}
\hline Source of variation & df & SS & $\begin{array}{c}\text { Variance } \\
\text { components }\end{array}$ & $\begin{array}{c}\text { Percentage of } \\
\text { variation }\end{array}$ \\
\hline Among populations & 10 & 18.575 & 0.012 & 0.97 \\
Among individuals & 215 & 293.571 & 0.115 & 9.13 \\
$\quad$ within populations & & & & 89.90 \\
Within individuals & 226 & 256.500 & 1.134 & \\
Total & 451 & 568.646 & 1.262 & \\
\hline
\end{tabular}

cesses for Hr13F06 ( $p<0.001$ ) (Appendix 1). There were missing genotypes when scoring locus Hr13F06 in 18 samples in 5 populations: Sydney Botany Bay (SYBB, $N=6$ ), Port Stephens (PS, $N=5$ ), Merimbula (MW, $\mathrm{N}=3$ ), Sydney Port Jackson (SYPJ, $\mathrm{N}=3$ ) and Narooma (NA, $N=1$ ). This suggests the presence of null alleles. This was confirmed using MICROCHECKER 2.2.3 which detected a significant proportion of null alleles $(p<0.001)$ in all populations for locus Hr13F06. Therefore, analyses were conducted including and excluding Hr13F06. Seven locus pairs showed significant evidence of linkage disequilibrium, but this was not consistent for any particular locus or population.

\section{Analyses of population genetic differentiation}

A multilocus AMOVA revealed weak but significant population subdivision with 5 loci (including Hr13F06: $\theta=0.009, \mathrm{p}<0.001$ ) and 4 loci (excluding Hr13F06: $\theta=$ 0.009, p < 0.001) (Table 3). Jackknifing over loci also showed the AMOVA pattern to be consistent and therefore not driven by outlier loci. Eleven out of a total of 55 pairwise $F_{\mathrm{ST}}$ were significant with either 4 or 5 loci, with MW and South West Rocks Fish Rock (SWFR) having 4 and 6 significant pairwise comparisons, respectively (Table 4). There was no significant correlation between $\theta$ and geographic distance with 4 loci $(p=0.688)$ or 5 loci $(\mathrm{p}=0.205)$. As a comparison, we also pooled pairs of populations with small sample sizes $(\mathrm{N}<15)$ that were located less than $10 \mathrm{~km}$ apart. This involved 2 pairs of populations: Eden Leonard Island (EDLI) and Eden Ross Bay (EDRB), and SWFR and South West Rocks Trial Bay (SWTB). Pooling of small sample size populations also resulted in a nonsignificant IBD result ( 5 loci: $\mathrm{p}=0.392$, 4 loci excluding Hr13F06: $\mathrm{p}=0.270$ ) and a weak but significant AMOVA result (5 loci: $\theta=0.012, \mathrm{p}<0.001$, 4 loci, excluding Hr13F06: $\theta=0.010, \mathrm{p}<0.001$ ).

\section{Multilocus spatial autocorrelation analysis}

The spatial autocorrelation analysis was carried out using 4 microsatellite loci due to the missing genotypes in some of the populations at locus Hr13F06. We detected significant positive spatial autocorrelation for individuals within the same population $(\mathrm{p}=0.003)$ and up to $20 \mathrm{~km}$ apart ( $\mathrm{p}=0.016$, Fig. 2). Therefore pairs of individuals within this spatial scale are more genetically similar than random. The autocorrelation signal then becomes significantly negative at 80 and $100 \mathrm{~km}$. If spatial autocorrelation is positive at some distances, it must be negative at others (Smouse \& Peakall 1999). Oscillations between low and high autocorrelation after $80 \mathrm{~km}$ suggest the pattern becomes fairly random at greater distances. When this analysis was jackknifed over loci, the same pattern of significant positive spatial autocorrelation for individuals within the same population and up to $20 \mathrm{~km}$ apart was detected when loci Hr11a10, Hr12b10 and Hr10b10 were individually excluded. When locus Hr9b05 was excluded there was significant positive spatial autocorrelation only for individuals within the same population.

Table 4. Haliotis coccoradiata. Pairwise $F_{\mathrm{ST}}(\theta)$ values among 11 populations in southeastern Australia. The $\theta$ values marked * and ${ }^{* *}$ are significant at $5 \%$ and $1 \%$ levels, respectively. Abbreviations as in Table 1

\begin{tabular}{|c|c|c|c|c|c|c|c|c|c|c|}
\hline & EDRB & EDLI & MW & $\mathrm{BE}$ & NA & JB & PS & SYPJ & SYBB & SWFR \\
\hline EDLI & -0.009 & & & & & & & & & \\
\hline MW & 0.007 & -0.001 & & & & & & & & \\
\hline $\mathrm{BE}$ & 0.000 & 0.000 & 0.013 & & & & & & & \\
\hline NA & 0.017 & 0.021 & $0.036^{* *}$ & $0.016^{*}$ & & & & & & \\
\hline JB & 0.014 & 0.013 & $0.025^{* *}$ & 0.005 & -0.002 & & & & & \\
\hline PS & 0.002 & 0.016 & $0.022^{* *}$ & 0.002 & 0.006 & -0.002 & & & & \\
\hline SYPJ & -0.005 & 0.008 & $0.019^{*}$ & 0.006 & 0.004 & -0.001 & -0.009 & & & \\
\hline SYBB & -0.004 & -0.003 & 0.006 & 0.005 & 0.006 & 0.006 & 0.021 & 0.012 & & \\
\hline SWFR & 0.014 & -0.007 & 0.008 & $0.036^{* *}$ & $0.049^{* *}$ & $0.034^{* *}$ & $0.044^{* *}$ & $0.029^{* *}$ & $0.025^{* *}$ & \\
\hline SWTB & -0.012 & -0.013 & 0.029 & 0.003 & -0.008 & -0.000 & 0.006 & -0.001 & -0.005 & 0.019 \\
\hline
\end{tabular}




\section{Computer simulations}

Our spatial autocorrelation results are suggestive of short-distance dispersal and local recruitment. However, the computer simulations we used in which all dispersal was restricted to within this scale (mean $10 \mathrm{~km}$ ) suggested that significant IBD would most likely be generated under such a dispersal scenario. When the proportion of dispersers was only $0.01, \sim 50 \%$ of simulations yielded a significant IBD pattern over the scale of the study. At higher migration rates (0.05 to 0.5), a significant IBD pattern was observed in $100 \%$ of replicates.

\section{Particle dispersal modelling}

Particle dispersal modelling suggests larvae could be transported over large distances by ocean currents. There was variation in the possible particle dispersal distances within and between the 3 locations, ranging from an overall mean distance of $176.84 \mathrm{~km}$ at Sydney to $353.67 \mathrm{~km}$ at South West Rocks for the period 1995 to 1999 (Table 5).

\section{DISCUSSION}

In this study we detected weak but significant genetic differentiation $(\theta)$ over a large scale $(\sim 1000 \mathrm{~km})$, as well as fine-scale multilocus spatial autocorrelation $(\sim 20 \mathrm{~km})$ in Haliotis coccoradiata, a broadcast spawning marine mollusc with pelagic larvae. Positive local spatial autocorrelation has been associated with restricted dispersal and can indicate local recruitment (Underwood et al. 2007). Therefore, our finding of significant positive spatial autocorrelation within $20 \mathrm{~km}$ may be indicative of a certain proportion of dispersal events being restricted to this scale. This conclusion is consistent with ecological, behavioural and genetic studies on other Haliotis species (Prince et al. 1987, McShane et al. 1988, Chambers et al. 2006, Temby et al. 2007).

Although weak but significant genetic differentiation was detected over the sampled range of the species, there was no evidence of an IBD relationship. The level of differentiation among the populations was $\theta=$ 0.012 , lower than $F_{\mathrm{ST}}$ values detected in other studies of molluscs (e.g. 0.067 in Evans et al. 2004; 0.06 in Chambers et al. 2006). A non-significant IBD pattern (Palumbi 2003) and low $F_{\mathrm{ST}}$ may be interpreted as resulting from long distance dispersal by Haliotis COCcoradiata. Indeed, oceanographic modelling of particle dispersal suggested that if local larval retention is not facilitated by processes such as larval swimming behaviour or coastal disruptions to ocean current patterns, $H$. coccoradiata has the potential to disperse over several hundred kilometers along the south east coast of Australia. While this may be an extreme upper limit to the dispersal potential of this species, our results from the genetic differentiation analyses were inconsistent with a simple simulated model of dispersal restricted to a local scale. Therefore, while the multilocus spatial autocorrelation results are indicative of some degree of larval retention and recruitment within a $20 \mathrm{~km}$ scale, our findings on large-scale patterns of genetic differentiation suggest that a certain proportion of dispersal events occur over larger distances.

In some studies, fine-scale genetic structure in marine invertebrates has been identified as a pattern of random 'patchiness' (Johnson \& Black 1984, Johnson \& Wernham 1999, Banks et al. 2007). Spatial variation in allele frequencies as a result of temporal genetic differences among cohorts of larval recruits, together with patchy settlement, can cause fine scale genetic differentiation among adults (Johnson \& Black 1984, Johnson \& Wernham 1999). This mechanism may generate fine-scale structure in the absence of restricted dispersal. However, we believe it is unlikely that this is the explanation for

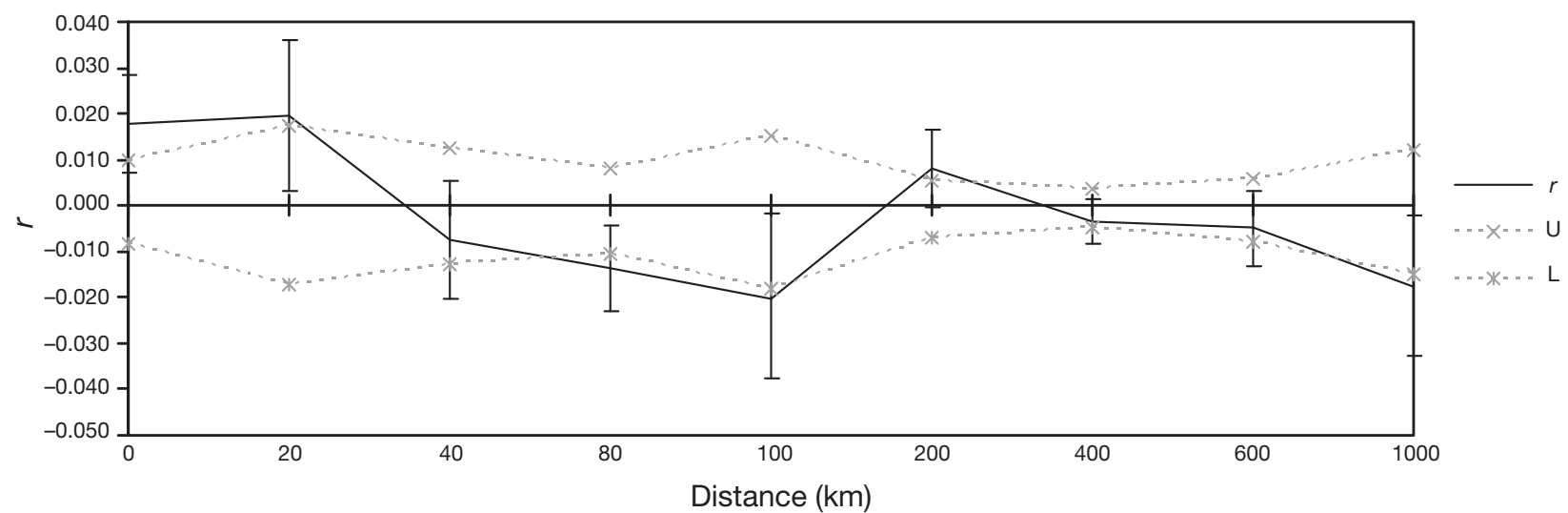

Fig. 2. Haliotis coccoradiata. Spatial autocorrelation coefficient $(r)$ for microsatellite data over a range of geographic distance classes for all individuals sampled with a $95 \%$ confidence level (U, L: upper and lower confidence limits, respectively) 
Table 5. Dispersal distances $(\mathrm{km})$ for particles with a planktonic duration of $10 \mathrm{~d}$-similar to the estimated planktonic duration for Haliotis coccoradiata larvae - for 3 different locations along the new South Wales coast over the $5 \mathrm{yr}$ period on the Aus-ConnIe (Condie et al. 2005) interface (1995-1999). Dispersal probabilities for each year were calculated as a mean for the months of November, January and March

\begin{tabular}{|lccccc|}
\hline Year & $\begin{array}{c}\text { South West } \\
\text { Rocks }\end{array}$ & Sydney & $\begin{array}{c}\text { Jervis } \\
\text { Bay }\end{array}$ & Mean & SD \\
\hline 1995 & 354.35 & 181.84 & 230.21 & 255.47 & 88.98 \\
1996 & 279.65 & 150.49 & 155.72 & 195.29 & 73.10 \\
1997 & 397.48 & 172.23 & 169.29 & 246.34 & 130.90 \\
1998 & 446.11 & 149.61 & 200.05 & 265.26 & 158.64 \\
1999 & 290.75 & 230.04 & 267.67 & 262.82 & 30.64 \\
Mean & 353.67 & 176.84 & 204.59 & 245.03 & 96.45 \\
SD & 70.53 & 32.83 & 45.52 & 95.09 & \\
\hline
\end{tabular}

the fine-scale genetic structure detected here. The spatial autocorrelation results are more consistent with restricted dispersal than with genetic patchiness. The correlogram follows the expected pattern of restricted gene flow: positive spatial genetic autocorrelation at short distance classes, subsequently declining through zero and becoming negative (Smouse \& Peakall 1999). The positive spatial autocorrelation pattern was found not only within a location but also extended to a range up to $20 \mathrm{~km}$. Therefore we suggest that our finding of finescale structure relates to localized recruitment of larvae (as suggested for Haliotis rubra by Temby et al. 2007), as opposed to random genetic patchiness.

Ecological and behavioural studies on abalone suggest local larval retention occurs and supports our conclusion of restricted dispersal and local recruitment in Haliotis coccoradiata (McShane et al. 1988, Chambers et al. 2006). Larvae of many species can move vertically in the water column and may be able to take advantage of local currents and tides (Cowen et al. 2000, Bilton et al. 2002). As discussed by Queiroga \& Blanton (2004), larval behaviour is an important influence on dispersal, as vertical migration in the water column in response to marine physical processes can result in different temporal and spatial scales of dispersal. McShane et al. (1988) suggest that settlement of $H$. rubra larvae would be most successful if the larvae remained on the parental reef. In addition, high recruitment of abalone larvae was observed in sheltered habitat (large boulders, kelp forests and weak currents). Adults may assist in local settlement of larvae by spawning in calm conditions or in areas with sheltered habitat (McShane et al. 1988). In addition to biological and ecological factors, local ocean currents and coastal topography may also play an important role in local recruitment of $H$. coccoradiata. Other studies have shown that water currents as well as coastal topography can result in larvae remaining longer in some regions than others which may promote larval retention (McShane et al. 1988, Banks et al. 2007). O'Connor et al. (2007) modeled the effects of temperature on larval development on a range of marine taxa and found that water temperature is also likely to have a striking effect on the dispersal distance of marine larvae. The temperature difference between the southernmost (Eden) and northernmost (South-West Rocks) sampling sites is approximately $5^{\circ} \mathrm{C}$ during the months of reproduction; thus it is possible that the warmer temperatures in the northern part of the species' range may result in less dispersal in the north compared to the south. However, the influence of temperature was difficult for us to assess given the difficulties in finding northern sampling sites due to the lower incidence of rocky reef habitat compared to the south.

\section{CONCLUSIONS}

We identified fine scale genetic structure consistent with some degree of local larval retention in a species with the ability to disperse over considerably greater distances. While our sampling and genetic data do not enable us to estimate precise dispersal distributions, it is likely that the interaction between large-scale ocean current patterns, their disruption by nearshore coastal and benthic topography, and larval behaviour results in complex dispersal distributions that are not easily estimated by large-scale patterns of population genetic differentiation. Despite our small sample sizes, our results were corroborated by different analyses and significance patterns were supported after jackknifing over loci, which suggests our results were not driven by outlier loci. Although Haliotis coccoradiata is not a commercial abalone species, we can infer from our findings some local recruitment for other abalone, such as $H$. rubra, which may be subject to over-fishing. As discussed by Temby et al. (2007), removal of adults from an area may result in a reduction in recruitment to an area and cause a local population collapse. Therefore, in addition to relying on marine reserves and marine protected areas for conserving such species, it is important that fisheries managers incorporate this type of data into fisheries management plans (Temby et al. 2007).

Acknowledgements. We thank K. Newton, U. Bové (the abmaster), P. McCracken, J. Williamson and P. Hallam for sample collection. Thanks to Neil J. Holbrook for discussions on oceanography. Samples were collected under NSW DPI research permit 05/0090 and Booderee NP permit BDR05/ 00011. The MEGMAR research project is supported by a Macquarie University Research Innovation Fund grant (MQA006162 grant to L.B.B). 


\section{LITERATURE CITED}

Ault JS (1985) Species profiles: life histories and environmental requirements of coastal fishes and invertebrates (Pacific Southwest)-black, green, and red abalones. USFWS Biol Rep 82

Balloux F (2001) EASYPOP (version 1.7): a computer program for population genetic simulations. J Hered 92:301-302

Banks SC, Piggott MP, Williamson JE, Bové U, Holbrook NJ, Beheregaray LB (2007) Oceanic variability and coastal topography shape local genetic structure in a longdispersing sea urchin. Ecology 88:3055-3064

Baranski M, Rourke M, Loughnan S, Austin C, Robinson N (2006) Isolation and characterization of 125 microsatellite DNA markers in the blacklip abalone, Haliotis rubra. Mol Ecol Notes 6:740-746

Bell JJ, Okamura B (2005) Low genetic diversity in marine nature reserve: re-evaluating diversity criteria in reserve design. Proc R Soc Lond B Biol Sci 272:1067-1074

Bilton DT, Paula J, Bishop JDD (2002) Dispersal, genetic differentiation and speciation in estuarine organisms. Estuar Coast Shelf Sci 55:937-952

Brookfield JFY (1996) A simple new method for estimating null allele frequency from heterozygote deficiency. Mol Ecol 5:453-455

> Chambers MD, Van Blaricom GR, Hauser L, Utter F, Friedman CS (2006) Genetic structure of black abalone (Haliotis cracherodii) populations in the California islands and central California coast: impacts of larval dispersal and decimation from withering syndrome. J Exp Mar Biol Ecol 331:173-185

> Condie SA, Waring J, Mansbridge ML, Cahill ML (2005) Marine connectivity patterns around the Australian continent. Environ Model Softw 20:1149-1157

> Cowen RK, Lwiza KM, Sponaugle S, Paris CB, Olson DB (2000) Connectivity of marine populations: open or closed? Science 287:857-859

Di Rienzo A, Peterson AC, Garza JC, Valdes AM, Slatkin M, Freimer NB (1994) Mutational processes of simple sequence repeat loci in human populations. Proc Natl Acad Sci USA 91:3166-3170

Edgar GJ (2000) Australian marine life: the plants and animals of temperate waters. Reed New Holland, Sydney

Evans B, White RWG, Elliot NG (2000) Characterisation of microsatellite loci in the Australian blacklip abalone (Haliotis rubra, Leach). Mol Ecol 9:1183-1184

Evans BS, Sweijd NA, Bowie RCK, Cook PA, Elliot NG (2004) Population genetic structure of the perlemoen Haliotis midae in South Africa: evidence of range expansion and founder effects. Mar Ecol Prog Ser 270:163-172

Flowers JM, Schroeter SC, Burton RS (2002) The recruitment sweepstakes has many winners: genetic evidence from the sea urchin Strongylocentrotus purpuratus. Evolution 56:1445-1453

Guo SW, Thompson EA (1992) Performing the exact test of Hardy-Weinberg proportion for multiple alleles. Biometrics 48:361-372

Hellberg ME, Burton RS, Neigel JE, Palumbi SR (2002) Genetic assessment of connectivity among marine populations. Bull Mar Sci 70:273-290

> Jarne P, Lagoda PJL (1996) Microsatellites, from molecules to populations and back. Trends Ecol Evol 11:424-429

> Johnson MS, Black R (1984) Pattern beneath the chaos: the effect of recruitment on genetic patchiness in an intertidal limpet. Evolution 38:1371-1383

> Johnson MS, Wernham J (1999) Temporal variation of recruits as a basis of ephemeral genetic heterogeneity in the western rock lobster Panulirus cygnus. Mar Biol 135:133-139
Jones GP, Planes S, Thorrold SR (2005) Coral reef fish larvae settle close to home. Curr Biol 15:1314-1318

Kinlan BP, Gaines SD, Lester SE (2005) Propagule dispersal and the scales of marine community process. Divers Distrib 11:139-148

McShane PE (1992) Early life history of abalone: a review. In: Shepherd SA, Tegner MJ, Guzman del Proo SA (eds) Abalone of the world. Biology, fisheries and culture. Fishing News Books, Oxford

McShane PE, Black KP, Smith MG (1988) Recruitment processes in Haliotis rubra (Mollusca: Gastropoda) and regional hyrdodynamics in southeastern Australia imply localized dispersal of larvae. J Exp Mar Biol Ecol 124: 175-203

Morse ANC, Morse DE (1984) Recruitment and metamorphosis of Haliotis larvae induced by molecules uniquely available at the surface of crustose red algae. J Exp Mar Biol Ecol 75:191-215

> O'Connor MI, Bruno JF, Gaines SD, Halpern BS, Lester SE, Kinlan BP, Weiss JM (2007) Temperature control of larval dispersal and the implications for marine ecology, evolution and conservation. Proc Natl Acad Sci USA 104: 1266-1271

> Palumbi SR (1994) Genetic divergence, reproductive isolation, and marine speciation. Annu Rev Ecol Syst 25: 547-572

Palumbi SR (2003) Population genetics, demographic connectivity, and the design of marine reserves. Ecol Appl 13: 146-158

Peakall R, Smouse PE (2006) GenAlEx 6: genetic analysis in Excel. Population genetic software for teaching and research. Mol Ecol Notes 6:288-295

Prince JD, Sellers TL, Ford WB, Talbot SR (1987) Experimental evidence for limited dispersal of haliotid larvae (genus: Haliotis; Mollusca, Gastropoda). J Exp Mar Biol Ecol 106: 243-263

Queiroga H, Blanton J (2004) Interactions between behaviour and physical forcing in the control of horizontal transport of decapod crustacean larvae. Adv Mar Biol 47:107-214

Raymond M, Rousset F (2003) GENEPOP, version 3.4: population genetics software for exact tests and ecumenicism. J Hered 86:248-249

Roberts RD, Lapworth C (2001) Effect of delayed metamorphosis on larval competence, and post-larval survival and growth, in the abalone Haliotis iris Gmelin. J Exp Mar Bio Ecol 258:1-13

Schneider S, Roessli D, Excoffier L (2000) ARLEQUIN: a software for population genetic data analysis, version 2.000. Genetics and Biometry Laboratory, Department of Anthropology, University of Geneva

> Shepherd SA, Laws HM (1974) Studies on southern Australian abalone (Genus Haliotis). II. Reproduction of five species. Aust J Mar Freshw Res 25:49-62

Shepherd SA, Turner LA (1985) Studies on southern Australian abalone (genus Haliotis). VI. Habitat preference and abundance and predators of juveniles. J Exp Mar Biol Ecol 93:285-298

Shipley P (2003) MICRO-CHECKER, version 2.2.3. Department of Biological Science, University of Hull

Smouse PE, Peakall R (1999) Spatial autocorrelation analysis of individual multiallele and multilocus genetic structure. Heredity 82:561-573

Sponaugle S, Lee T, Kourafalou V, Pinkard D (2005) Florida current frontal eddies and the settlement of coral reef fishes. Limnol Oceanogr 50:1033-1048

> Stephens SA, Broekhuizen N, Macdiarmia AB, Lundquist CJ, Mcleod L, Haskew R (2006) Modelling transport of larval New Zealand abalone (Haliotis iris) along an open coast. Mar Freshw Res 57:519-532 
Sunnucks P, Hales DF (1996) Numerous transposed sequences of mitochondrial cytochrome oxidase I-II in aphids of the genus Sitobion (Hemiptera: Aphidae). Mol Biol Evol 13: 510-524

Swearer SE, Caselle JE, Lea DW, Warner RR (1999) Larval retention and recruitment in an island population of a coral-reef fish. Nature 402:799-802

Temby N, Miller K, Mundy C (2007) Evidence of genetic sub- division among populations of blacklip abalone (Haliotis rubra Leach) in Tasmania. Mar Freshw Res 58:733-742 Underwood JN, Smith LD, Van Oppen MJH, Gilmour JP (2007) Multiple scales of genetic connectivity in a brooding coral on isolated reefs following catastrophic bleaching. Mol Ecol 16:771-784

Weir BS, Cockerham CC (1984) Estimating F-statistics for the analysis of population structure. Evolution 38:1358-1370

Appendix 1. Haliotis coccoradiata. Allele frequencies and summary statistics of genetic diversity of 11 populations (sample size in parentheses; see Table 1 for full names of sites). $N a$, observed number of alleles; $H_{E}$, expected heterozygosity based on Nei's unbiased estimate; $H_{\mathrm{O}}$, observed heterozygosity; $F_{\mathrm{IS}}$, the inbreeding coefficient based on Weir \& Cockerham (1984). $F_{\mathrm{IS}}$ values marked * are significant at $1 \%$ levels

\begin{tabular}{|c|c|c|c|c|c|c|c|c|c|c|c|c|}
\hline Locus & & $\begin{array}{c}\text { EDRB } \\
\text { (8) }\end{array}$ & $\begin{array}{c}\text { EDLI } \\
(14)\end{array}$ & $\begin{array}{c}\text { MW } \\
(37)\end{array}$ & $\begin{array}{c}\mathrm{BE} \\
(21)\end{array}$ & $\begin{array}{l}\text { NA } \\
(30)\end{array}$ & $\begin{array}{l}\text { JB } \\
(31)\end{array}$ & $\begin{array}{c}\text { SYBB } \\
(18)\end{array}$ & $\begin{array}{c}\text { SYPJ } \\
(25)\end{array}$ & $\begin{array}{l}\text { PS } \\
\text { (23) }\end{array}$ & $\begin{array}{c}\text { SWFR } \\
(13)\end{array}$ & $\begin{array}{c}\text { SWTB } \\
(6)\end{array}$ \\
\hline \multirow[t]{32}{*}{ Hr12B10 } & 192 & - & 0.036 & 0.014 & - & - & - & - & - & - & - & - \\
\hline & 195 & _ & - & 0.014 & 0.048 & _- & - & _ & 0.040 & 0.022 & 0.077 & - \\
\hline & 198 & 0.063 & _- & 0.014 & 0.024 & 0.033 & 0.048 & - & 0.020 & 0.043 & - & 0.083 \\
\hline & 201 & - & 0.107 & 0.041 & 0.095 & 0.050 & 0.113 & 0.056 & - & 0.065 & 0.077 & 0.167 \\
\hline & 202 & _- & - & - & - & - & - & - & - & 0.022 & - & - \\
\hline & 203 & - & - & - & - & - & - & - & - & - & 0.038 & - \\
\hline & 204 & 0.313 & 0.250 & 0.203 & 0.167 & 0.283 & 0.145 & 0.250 & 0.240 & 0.174 & 0.192 & 0.250 \\
\hline & 205 & 0.063 & - & - & - & - & - & - & - & - & - & - \\
\hline & 207 & 0.063 & 0.107 & 0.189 & 0.071 & 0.133 & 0.194 & 0.167 & 0.200 & 0.130 & 0.192 & - \\
\hline & 208 & - & - & - & - & 0.017 & - & - & - & - & - & - \\
\hline & 209 & 0.063 & - & - & - & - & - & - & - & - & 0.038 & - \\
\hline & 210 & 0.063 & 0.107 & 0.189 & 0.119 & 0.050 & 0.097 & 0.111 & 0.060 & 0.087 & 0.192 & _- \\
\hline & 212 & - & - & - & - & - & - & - & - & - & 0.038 & - \\
\hline & 213 & - & 0.107 & 0.122 & 0.119 & 0.117 & 0.081 & 0.028 & 0.160 & 0.174 & 0.077 & 0.167 \\
\hline & 215 & - & - & - & - & - & - & - & - & - & - & 0.083 \\
\hline & 216 & 0.125 & 0.107 & 0.054 & 0.167 & 0.100 & 0.161 & 0.194 & 0.060 & 0.109 & _- & 0.167 \\
\hline & 219 & 0.063 & 0.107 & 0.095 & 0.048 & 0.033 & 0.032 & 0.028 & 0.060 & 0.022 & 0.077 & 0.083 \\
\hline & 220 & - & - & - & 0.024 & - & - & - & - & - & - & - \\
\hline & 222 & 0.063 & 0.036 & 0.027 & - & 0.067 & 0.065 & 0.083 & 0.080 & 0.022 & - & - \\
\hline & 224 & - & - & - & 0.024 & - & - & - & - & - & - & - \\
\hline & 225 & - & - & 0.027 & - & 0.067 & 0.048 & - & 0.040 & 0.087 & - & - \\
\hline & 227 & 0.063 & - & - & - & - & - & - & - & - & - & - \\
\hline & 228 & - & 0.036 & - & - & 0.017 & 0.016 & - & 0.040 & 0.043 & _- & _ \\
\hline & 231 & - & - & 0.014 & 0.071 & 0.017 & - & 0.056 & - & - & - & - \\
\hline & 234 & 0.063 & _- & - & - & - & - & - & - & - & - & _ \\
\hline & 237 & - & - & - & - & - & - & 0.028 & - & - & - & - \\
\hline & 240 & - & _- & - & 0.024 & - & - & - & - & - & _- & _- \\
\hline & 243 & - & - & - & - & 0.017 & - & - & - & - & - & - \\
\hline & $\mathrm{Na}$ & 11 & 10 & 13 & 13 & 14 & 11 & 10 & 11 & 13 & 10 & 7 \\
\hline & $H_{\mathrm{E}}$ & 0.852 & 0.865 & 0.890 & 0.857 & 0.861 & 0.877 & 0.844 & 0.854 & 0.886 & 0.861 & 0.833 \\
\hline & $H_{\mathrm{O}}$ & 1.00 & 0.857 & 0.857 & 0.865 & 0.867 & 0.871 & 0.722 & 0.880 & 0.957 & 0.846 & 1.000 \\
\hline & $F_{\mathrm{IS}}$ & -0.174 & 0.009 & 0.037 & -0.009 & -0.006 & 0.007 & 0.144 & -0.030 & -0.080 & 0.017 & -2.00 \\
\hline \multirow{20}{*}{ Hr10B10 } & 154 & - & 0.071 & - & - & - & - & - & - & - & - & - \\
\hline & 177 & - & - & 0.014 & - & - & - & - & - & - & - & - \\
\hline & 178 & - & - & 0.027 & - & - & - & - & - & - & - & - \\
\hline & 180 & - & 0.107 & 0.014 & 0.071 & 0.033 & - & _- & - & 0.022 & - & - \\
\hline & 181 & - & - & 0.135 & - & 0.017 & 0.032 & 0.028 & 0.020 & 0.065 & - & - \\
\hline & 182 & - & - & 0.014 & - & - & - & - & - & - & 0.038 & - \\
\hline & 183 & 0.188 & 0.107 & 0.108 & 0.190 & 0.067 & 0.113 & 0.194 & 0.160 & 0.065 & - & 0.167 \\
\hline & 185 & - & - & - & - & 0.017 & 0.016 & - & - & - & 0.038 & - \\
\hline & 186 & - & - & 0.068 & - & - & - & - & - & - & 0.038 & _- \\
\hline & 188 & 0.125 & 0.071 & 0.162 & 0.262 & 0.350 & 0.290 & 0.222 & 0.240 & 0.304 & - & 0.167 \\
\hline & 189 & - & 0.071 & - & - & 0.017 & - & 0.028 & - & - & - & - \\
\hline & 190 & 0.250 & 0.286 & 0.203 & 0.119 & 0.267 & 0.194 & 0.333 & 0.220 & 0.174 & 0.346 & 0.500 \\
\hline & 192 & - & 0.036 & 0.014 & 0.024 & 0.033 & 0.113 & - & 0.080 & 0.043 & 0.115 & - \\
\hline & 193 & _- & _- & - & - & - & 0.016 & _- & - & - & - & _- \\
\hline & 194 & - & 0.107 & 0.081 & 0.024 & 0.050 & 0.113 & 0.083 & 0.080 & 0.043 & 0.154 & - \\
\hline & 196 & 0.250 & 0.036 & 0.135 & 0.071 & 0.067 & 0.065 & 0.111 & 0.140 & 0.196 & 0.038 & - \\
\hline & 197 & - & - & 0.014 & - & - & - & - & 0.020 & - & - & - \\
\hline & 198 & 0.125 & 0.036 & 0.014 & 0.024 & 0.050 & 0.032 & - & 0.020 & 0.065 & 0.192 & 0.083 \\
\hline & 199 & - & - & - & 0.048 & - & - & - & - & - & 0.038 & - \\
\hline & 200 & - & - & - & - & 0.033 & - & - & - & - & - & - \\
\hline
\end{tabular}


Appendix 1 (continued)

\begin{tabular}{|c|c|c|c|c|c|c|c|c|c|c|c|c|}
\hline Locus & & $\begin{array}{c}\text { EDRB } \\
(8)\end{array}$ & $\begin{array}{c}\text { EDLI } \\
(14)\end{array}$ & $\begin{array}{r}\text { MW } \\
(37)\end{array}$ & $\begin{array}{l}\mathrm{BE} \\
(21)\end{array}$ & $\begin{array}{l}\text { NA } \\
(30)\end{array}$ & $\begin{array}{l}\text { JB } \\
(31)\end{array}$ & $\begin{array}{l}\text { SYBB } \\
(18)\end{array}$ & $\begin{array}{l}\text { SYPJ } \\
(25)\end{array}$ & $\begin{array}{l}\text { PS } \\
(23)\end{array}$ & $\begin{array}{c}\text { SWFR } \\
\text { (13) }\end{array}$ & $\begin{array}{c}\text { SWTB } \\
(6)\end{array}$ \\
\hline \multirow{34}{*}{ Hr13F06 } & 202 & - & 0.036 & - & 0.024 & - & 0.016 & - & - & 0.022 & - & - \\
\hline & 203 & - & - & - & - & - & - & _- & 0.020 & - & - & - \\
\hline & 204 & - & - & - & 0.071 & - & - & - & - & - & - & - \\
\hline & 205 & - & - & - & - & - & - & - & - & - & - & 0.083 \\
\hline & 206 & - & 0.036 & - & 0.048 & - & - & - & - & - & - & - \\
\hline & 210 & 0.063 & - & - & - & - & - & - & - & - & - & - \\
\hline & 213 & - & - & - & 0.024 & - & - & - & - & - & - & - \\
\hline & $\mathrm{Na}$ & 6 & 12 & 13 & 14 & 12 & 11 & 7 & 10 & 10 & 9 & 5 \\
\hline & $H_{\mathrm{E}}$ & 0.805 & 0.862 & 0.858 & 0.871 & 0.788 & 0.833 & 0.781 & 0.834 & 0.821 & 0.799 & 0.681 \\
\hline & $H_{\mathrm{O}}$ & 0.875 & 0.714 & 0.810 & 0.784 & 0.900 & 0.871 & 0.722 & 0.760 & 0.783 & 0.769 & 0.833 \\
\hline & $F_{\mathrm{IS}}$ & -0.087 & 0.172 & 0.057 & 0.101 & -0.142 & -0.046 & 0.075 & 0.089 & 0.047 & 0.037 & -0.244 \\
\hline & 196 & - & - & 0.015 & - & 0.034 & 0.016 & - & - & - & - & - \\
\hline & 198 & - & - & - & - & - & - & - & - & - & - & 0.083 \\
\hline & 204 & - & - & 0.029 & - & - & - & - & - & - & - & - \\
\hline & 205 & - & - & 0.029 & - & - & - & - & - & - & - & - \\
\hline & 206 & 0.125 & 0.143 & 0.088 & - & 0.034 & 0.113 & 0.167 & 0.045 & 0.056 & - & 0.417 \\
\hline & 208 & 0.250 & - & 0.103 & 0.048 & 0.138 & - & 0.208 & 0.114 & - & 0.077 & 0.167 \\
\hline & 216 & 0.063 & 0.107 & 0.088 & 0.095 & 0.052 & 0.145 & - & 0.023 & 0.056 & 0.154 & - \\
\hline & 217 & - & - & - & 0.048 & - & - & - & - & - & - & - \\
\hline & 218 & 0.125 & 0.536 & 0.412 & 0.595 & 0.655 & 0.387 & 0.292 & 0.432 & 0.583 & 0.500 & 0.167 \\
\hline & 219 & - & - & 0.015 & - & 0.034 & - & - & - & - & - & - \\
\hline & 220 & 0.063 & 0.071 & 0.015 & 0.048 & - & - & 0.167 & 0.136 & 0.139 & 0.154 & - \\
\hline & 221 & - & - & - & - & - & - & - & 0.068 & - & - & - \\
\hline & 222 & - & - & 0.029 & - & - & 0.032 & 0.167 & - & 0.167 & 0.077 & - \\
\hline & 223 & 0.188 & 0.143 & 0.176 & 0.095 & 0.034 & 0.210 & - & 0.159 & - & - & - \\
\hline & 224 & - & - & - & - & - & - & - & 0.023 & - & 0.038 & - \\
\hline & 225 & 0.188 & - & - & 0.071 & 0.017 & 0.048 & - & - & - & - & - \\
\hline & 227 & - & - & - & - & - & 0.016 & - & - & - & - & 0.167 \\
\hline & 230 & - & - & - & - & - & 0.016 & - & - & - & - & - \\
\hline & 232 & - & - & - & - & - & 0.016 & - & - & - & - & - \\
\hline & $\mathrm{Na}$ & 7 & 5 & 7 & 11 & 8 & 10 & 5 & 8 & 5 & 6 & 5 \\
\hline & $H_{\mathrm{E}}$ & 0.828 & 0.862 & 0.616 & 0.770 & 0.544 & 0.768 & 0.788 & 0.749 & 0.606 & 0.689 & 0.736 \\
\hline & $H_{\mathrm{O}}$ & 0.250 & 0.071 & 0.190 & 0.235 & 0.207 & 0.290 & 0.167 & 0.364 & 0.167 & 0.231 & 0.167 \\
\hline & $F_{\mathrm{IS}}$ & $0.698^{*}$ & $0.891^{*}$ & $0.691^{*}$ & $0.694^{*}$ & $0.620^{*}$ & $0.622^{*}$ & $0.789^{*}$ & $0.514^{*}$ & $0.725^{*}$ & $0.665^{*}$ & $0.774^{*}$ \\
\hline \multirow[t]{18}{*}{ Hr9B05 } & 170 & - & - & 0.027 & - & - & - & - & - & - & - & - \\
\hline & 177 & - & - & - & - & - & - & - & 0.020 & - & - & - \\
\hline & 178 & 0.125 & - & - & - & 0.017 & - & 0.028 & - & - & - & - \\
\hline & 179 & - & - & - & - & - & - & - & 0.040 & - & - & - \\
\hline & 180 & 0.063 & 0.071 & 0.054 & 0.095 & 0.333 & 0.274 & 0.167 & 0.180 & 0.152 & 0.077 & 0.250 \\
\hline & 181 & - & - & 0.014 & 0.024 & - & 0.016 & - & - & 0.022 & - & - \\
\hline & 182 & 0.813 & 0.857 & 0.892 & 0.738 & 0.633 & 0.694 & 0.750 & 0.720 & 0.739 & 0.923 & 0.750 \\
\hline & 183 & - & - & - & 0.024 & - & - & - & 0.020 & - & - & - \\
\hline & 188 & - & - & - & 0.048 & - & - & - & - & - & - & - \\
\hline & 192 & - & - & - & 0.024 & - & - & - & - & - & - & - \\
\hline & 202 & - & - & - & 0.024 & - & - & - & - & - & - & - \\
\hline & 258 & - & - & - & 0.024 & - & - & - & 0.020 & 0.022 & - & - \\
\hline & 262 & - & 0.071 & 0.014 & - & 0.017 & 0.016 & 0.056 & - & 0.043 & - & - \\
\hline & 268 & - & - & - & - & - & - & - & - & 0.022 & - & - \\
\hline & $\mathrm{Na}$ & 3 & 3 & 8 & 5 & 4 & 4 & 4 & 6 & 2 & 2 & \\
\hline & $H_{\mathrm{E}}$ & 0.320 & 0.255 & 0.441 & 0.201 & 0.487 & 0.443 & 0.406 & 0.446 & 0.142 & 0.375 & \\
\hline & $H_{\mathrm{O}}$ & 0.125 & 0.286 & 0.286 & 0.108 & 0.267 & 0.226 & 0.333 & 0.280 & 0.154 & 0.167 & \\
\hline & $F_{\mathrm{IS}}$ & 0.610 & -0.120 & $0.352^{*}$ & 0.461 & $0.453^{*}$ & $0.491^{*}$ & 0.179 & $0.373^{*}$ & -0.083 & 0.556 & \\
\hline \multirow[t]{12}{*}{ Hr11A10 } & 185 & - & - & - & 0.025 & - & - & - & - & - & - & - \\
\hline & 189 & 0.813 & 0.714 & 0.622 & 0.725 & 0.733 & 0.774 & 0.583 & 0.840 & 0.864 & 0.750 & 0.833 \\
\hline & 190 & - & - & 0.027 & - & - & - & 0.056 & 0.020 & 0.023 & 0.042 & - \\
\hline & 191 & 0.188 & 0.214 & 0.257 & 0.150 & 0.250 & 0.210 & 0.306 & 0.120 & 0.114 & 0.208 & 0.167 \\
\hline & 193 & - & - & - & 0.025 & - & 0.016 & 0.028 & - & - & - & - \\
\hline & 197 & - & - & 0.014 & - & - & - & - & - & - & - & - \\
\hline & 199 & - & - & 0.027 & - & - & - & - & - & - & - & - \\
\hline & 201 & - & 0.071 & 0.054 & 0.075 & 0.017 & - & 0.028 & 0.020 & - & - & - \\
\hline & $\mathrm{Na}$ & 2 & 3 & 5 & 6 & 3 & 3 & 5 & 4 & 3 & 3 & 2 \\
\hline & $H_{\mathrm{E}}$ & 0.305 & 0.439 & 0.445 & 0.543 & 0.399 & 0.356 & 0.562 & 0.279 & 0.241 & 0.392 & 0.278 \\
\hline & $H_{\mathrm{O}}$ & 0.125 & 0.500 & 0.450 & 0.405 & 0.400 & 0.323 & 0.389 & 0.280 & 0.273 & 0.500 & 0.333 \\
\hline & $F_{\mathrm{IS}}$ & 0.590 & -0.140 & -0.011 & 0.254 & -0.001 & 0.095 & 0.308 & $-0.003^{*}$ & -0.133 & -0.274 & -0.200 \\
\hline \multirow[t]{4}{*}{ All 5 loci } & Mean $N a$ & 5.80 & 6.60 & 9.60 & 9.80 & 8.20 & 7.80 & 6.20 & 7.80 & 7.40 & 6.00 & 4.20 \\
\hline & Mean $H_{\mathrm{E}}$ & 0.621 & 0.615 & 0.660 & 0.648 & 0.616 & 0.655 & 0.676 & 0.632 & 0.597 & 0.576 & 0.580 \\
\hline & Mean $H_{\mathrm{O}}$ & 0.475 & 0.485 & 0.524 & 0.479 & 0.528 & 0.516 & 0.467 & 0.513 & 0.496 & 0.500 & 0.500 \\
\hline & Mean $F_{\mathrm{IS}}$ & 0.327 & 0.162 & 0.235 & 0.300 & 0.184 & 0.234 & 0.299 & 0.189 & 0.159 & 0.072 & 0.141 \\
\hline
\end{tabular}

